\title{
Evidence-Based Management and its Application in the Hospital Management Process
}

\author{
Mohsen Saberi Isfeedvajani ${ }^{1 *}$ \\ ${ }^{1}$ Medicine, Quran and Hadith Research Center \& Department of Community Medicine, Faculty of Medicine, \\ Baqiyatallah University of Medical Sciences, Tehran, Iran \\ *Corresponding Author: Mohsen Saberi Isfeedvajani, M.D., Associate Professor, Medicine, Quran and Hadith \\ Research Center \& Department of Community Medicine, Faculty of Medicine, Baqiyatallah University of Medical \\ Sciences, Tehran, Iran. Tel:+98-21-81263617, Email: drsaberihaji@gmail.com
}

Received January 23, 2018; Accepted March 3, 2018; Online Published April 18, 2018

$\mathrm{T}$ he term "evidence-based" has been raised in healthcare and has become an important issue for clinicians, managers, and researchers. While clinicians are encouraged by the leaders and top management of health systems and hospitals to adopt an evidence-based approach in treating patients, these leaders and managers have not applied this approach to their own managerial practices. ${ }^{1,2}$

Evidence-based management means to apply the best evidence in organizational practices. ${ }^{2}$ It leads to managers becoming experts in order to make decisions based on the best scientific evidence available. ${ }^{3}$

Hospital committees serve as think tanks for hospital managers and can play the role of advisor and decisionmaker in achieving hospital goals based on the National Accreditation System of Hospitals approved by the Ministry of Health. ${ }^{4}$

It has been stated that a research practice gap exists between healthcare policy and management. Also, evidence-based management has been ignored in healthcare compared with evidence-based medicine. Unfortunately, leaders, policymakers, and managers, themselves, have no interest in applying this approach because of internal and external barriers to its use, such as the culture of decision-making based on evidence, managers' lack of adequate knowledge about the research process, managers' suspicions of the values of research and researchers, inadequate research dissemination, and a lack of external pressure for adopting researched practices. ${ }^{1,25,6}$

To overcome these barriers and persuade hospital managers and committees to apply evidence-based management and decision-making, the following actions are proposed ${ }^{1,5}$ :

\section{Build an Evidence-Based Culture}

The first and foremost step is to develop and promote a culture of "learning through research." If this culture is not institutionalized, efforts to deliver best available evidence to managers lead to frustration. Research evidence is more likely to be applied in an organization with a culture of supporting and encouraging innovation, experimentation, data collection, data analysis and interpretation, and the development and promotion of critical appraisal skills and competences among managers. ${ }^{1,5,7}$

\section{Obtain Evidence}

First, a great deal of attention should be paid to specifying the research question to ensure that the results will be applicable. Specific research questions are more likely to lead to results that will culminate in managerial actions. The ideal is that managers work collaboratively with academic researchers to develop the research question. Second, the selected question should be important to the organization. Specific operational questions are appropriate for evidence-based decision making; however, strategic questions are especially critical, because the viability of organization increases the chance of research application in the decision-making process. ${ }^{1,6,8}$

\section{Change the Way Decisions Are Made}

Research systems and their products should be redesigned to facilitate the decision-making process. First, there must be a match between the time the results are prepared and the time the decision should be made. Clearly, if a manager should make a decision before the research is completed, the research will not be used. ${ }^{1}$

Second, the results of research should be summarized and made easy for managers to understand. Managers are unlikely to read detailed research reports, but they are more likely to accept the executive summary of the research project, if prepared. Albeit, those who write and prepare the report and executive summary should be alert,

Copyright $\odot 2018$ The Author(s). This is an open-access article distributed under the terms of the Creative Commons Attribution License (http:// creativecommons.org/licenses/by/4.0), which permits unrestricted use, distribution, and reproduction in any medium, provided the original work is properly cited. 
because managers must make decisions based on the best scientific evidence available. ${ }^{1}$

Third, a substantial effort should be made to communicate the research results throughout the organization. Research results are used when the related authorities understand them at the time of decision-making. Specified systems need to be established in order to ensure that research results have been published in the organization and are in the hands of the relevant directors. These systems can include a website to provide an accessible, consolidated resource for evidence-based decision-making; academic journals that publish the results of research projects; e-mails containing research abstracts sent to the relevant decision makers. ${ }^{1}$

\section{Conflict of Interest Disclosures}

Author declares that he has no conflict of interests.

\section{Ethical Approval}

Not applicable.

\section{References}

1. Walshe K, Rundall TG. Evidence-based management: from theory to practice in health care. Milbank Q. 2001;79(3):429457, iv-v. doi:10.1111/1468-0009.00214.

2. Sharp D. Exploring evidence based management in the National Health Service. Nottingham Trent University; 2010.

3. Rousseau DM. Is there Such a thing as "Evidence-Based Management"? Acad Manage Rev. 2006;31(2):256-269. doi:10.5465/amr.2006.20208679.

4. Soroush A, Mohseni M, Komasi S, Baharirad N, Moradi F. The Use of Evidence by Decision-Making Committees. Hosp Pract Res. 2017;2(4):128. doi:10.15171/hpr.2017.31.

5. Greaves DE. Evidence-based management of Caribbean health systems: barriers and opportunities. Int J Health Gov. 2017;22(2):104-117. doi:10.1108/JJHG-01-2017-0001.

6. Gautam K. Addressing the research-practice gap in healthcare management. J Public Health Manag Pract. 2008;14(2):155159. doi:10.1097/01.PHH.0000311894.57831.4b.

7. Kovner AR, D'Aquila R, Fine DJ. Evidence-based management in healthcare. AUPHA: Health Administration Press; 2009.

8. Shortell SM. Promoting evidence-based management. Front Health Serv Manage. 2006;22(3):23-29. doi: 10.1097/01974520-200601000-00003. 